\title{
Young Offenders: Early Intervention For Students With Behavioral And Emotional Disorders
}

Helen Hammond, University of Texas, El Paso, USA Lawrence Ingalls, University of Texas, El Paso, USA

\begin{abstract}
The value of early intervention programs for children with delays and/or disabilities has been well accepted in the research. Providing appropriate special education services at an early age of detecting academic and behavioral/social problems has proven to be effective at eliminating or decreasing special services at a later age. This presentation will discuss the types of educational services provided to young offenders who are now incarcerated at a state prison. A description of 30 male inmates' academic history will be provided and patterns regarding the history will be discussed.
\end{abstract}

\section{INTRODUCTION}

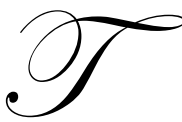

he benefits of early intervention programs for children who are at-risk for developing a disability or who have a disability or delay have been well documented in the research (APA Report on Youth Violence, 1994; Gonzalez-Mena,2006; Guralnick, 1997; Heward, 2006; Kaiser \& Rasminsky, 2003; Lerner, Lowenthal, \& Egan, 2003; Raver, 2009; Wolery \& Bailey, 2002; Zirpoli, 1995;). For decades professionals have advocated for early intervention programs to provide services for young children and families. The value of these programs became a reality in the United States when Congress passed into law Public Law 99457 in 1986. This law expanded the special education services to young children with disabilities from school age to three years of age. Additionally, the law provided a special set of services to families and young children with known disabilities and established at-risk conditions. This section of the law was for children birth to three years of age.

Through this law, which is now termed Public Law Individuals with Disabilities Education Act (P. L. IDEA), a wide array of programs can be provided to qualified children and families. Such services include special instruction, speech and language services, physical therapy, occupational therapy, counseling, transportation, and assistive technology to name a few. Of particular interest to this research is the special instruction that can be provided to young children with behavioral and/or emotional disorders. Through the early intervention program, children at an early age can be provided intense behavioral instruction to modify their behavior and to learn to display appropriate behaviors and reactions to their environment. With this early instruction, young children can make life long changes and be able to apply these new behaviors to the variety of settings of which they interact within their home, school and community settings.

\section{EARLY INTERVENTION BEHAVIOR PROGRAMS AND ANTISOCIAL BEHAVIORS}

Young children need to learn more than just the basic academic skills emphasized in our school settings. They must also acquire many social adaptive skills which are necessary to be successful in our communities. Some children have to be directly and intensely taught at a very early age social skills that other children their own age learn very naturally. Social skills such as self monitoring, self regulation, delayed gratification, and intrinsic monitoring of behaviors are some of the competencies that most children acquire as part of their natural development. However, some children require intensive therapy in order to acquire these skills. Thus, these 
specialized programs are a necessity for this group of children. Without the appropriate detection and training from these early programs, children may be destined for behavioral and academic failure which may lead into greater school and societal problems. Such problems may include school suspension, expulsion, alternative school placement, juvenile detention, drop out, and incarceration.

Previous research has found behavioral problems as a major reason why students with disabilities are expelled or removed from schools (Wagner, Neuman, Cameto, Levine, \& Marder, 2003). According to Kauffman (2005), students with emotional behavior disturbance (EBD) are less likely to graduate from high school and to attend post secondary institutions as compared to students with mild disabilities. Walker, Colvin \& Ramsey (1995) found that $20 \%$ of delinquents have been arrested after three years from leaving school. A report from the U.S. Department of Health and Human Services (1999) was even more alarming in their data. This report stated approximately $70 \%$ of EBD students would be arrested within three years of quitting school. Cullinan (2002) found that after three years of departing from school, a majority of students with EBD were unemployed, had been arrested, and were not living independently. According to the APA Report on Youth Violence (1994) in 1994 juveniles between the age of 10 and 17 years were responsible for $14 \%$ of all violent crimes in the United States. The report projected a 22\% increase in juvenile violent crimes by the year of 2010 .

Walker, et .al. (1995) clearly emphasized the value of early detection and programs for young children with antisocial behaviors. Their research concluded that if aggressive and antisocial behaviors are not changed by the end of third grade, this behavioral condition should be treated as a chronic condition similar to other medical problems like diabetes. Walker and his colleagues surmised that the antisocial behaviors will be lifelong problems and will only be managed with appropriate interventions and support.

There are many models of behavioral intervention for young children and their families who are facing concerns regarding behavioral problems. Some researchers emphasize the use of family centered interventions which address the needs of the family to best help their child to develop skills to learn and grow. Specific training can be provided to the family members to learn to carry-out behavioral programs within the home and community settings.

Other models emphasize the importance of general and special education teachers receiving training in implementing behavioral programs within the school setting. Some programs utilize reinforcement consequences for appropriate behavior while others utilize a punishment approach for inappropriate behaviors. Both approaches employ an extrinsic control over the child vs. the child exercising an intrinsic control over him or herself.

Recently research has begun to emphasize the importance of teachers providing programs that help instill intrinsic control over behaviors and emotions. With the implementation of these types of self-management programs, children are taught to self-monitor and self-regulate their skills (Paris \& Paris, 2001; Vaughn, Bos, \& Schumm, 2007; Walker, et.al., 1995; Webber \& Plotts, 2008;). This appears to be a key survival skill necessary for success in present and future school, home, and community settings.

\section{SCHOOL EXPERIENCES OF YOUNG OFFENDERS}

As an attempt to better understand the school experiences of young offenders who had been incarcerated, these researchers reviewed individual files and interviewed inmates at a medium security state prison. This file review and interview process occurred over a period of eight years. The time frame for this research was extensive as periodically the prison was on lock down due to inmate violence. Additionally, due to prison routines, the researchers of this study frequently were only able to review/interview a limited number of files/inmates per prison visit.

Thirty male inmates, all under the age of 22 years of age, provided descriptive information to major categories of inquiry regarding past school experiences and attitudes toward their academic and behavioral accomplishments and challenges. The major categories explored were the following: 1) qualification status for special education services; 2) evidence of behavioral problems at an early age prior to fourth grade; 3) evidence of academic problems prior to fourth grade; 4) a description of the special interventions provided to the individual; 5) 
placement in an alternative school setting; and 6) general recommendations from inmates regarding improving public school services. Preliminary findings from this data collection are summarized in the following section.

\section{PRELIMINARY FINDINGS}

As noted earlier, thirty inmates were interviewed and their files were reviewed to obtain a comprehensive depiction of the individuals' school experiences from early elementary through secondary education. Five major areas were identified to provide categories to better understand patterns of experiences, attitudes, and consequences of these experiences. The table below provides a summary of the data compiled from the analyses. A percentage of responses for each category has been calculated.

Table 1

\begin{tabular}{|c|c|c|c|c|}
\hline $\begin{array}{c}\text { Qualified For } \\
\text { Special Education }\end{array}$ & $\begin{array}{c}\text { Behavior Problems } \\
\text { Prior To 4 }\end{array}$ & $\begin{array}{c}\text { Academic Problems } \\
\text { Prior to 4 } 4^{\text {th }} \text { Grade }\end{array}$ & $\begin{array}{c}\text { Types of } \\
\text { Interventions For } \\
\text { Behavior }\end{array}$ & $\begin{array}{c}\text { Alternative School } \\
\text { Placements }\end{array}$ \\
\hline $67 \%(20 / 30)$ & $73 \%(22 / 30)$ & $73 \%(22 / 30)$ & $\begin{array}{c}77 \% \text { had no noted } \\
\text { behavior program } \\
(23 / 30) ; \\
17 \% \text { noted a } \\
\text { minor behavioral } \\
\text { program }(5 / 30) ;\end{array}$ & $90 \%(27 / 30)$ \\
\hline
\end{tabular}

Additional details regarding the calculations revealed that of those children identified as having a behavior problem prior to fourth grade, nineteen of the children were identified with serious behavior and/emotional problems and academic difficulties by first or second grade (63\%). Three more children were identified with serious behavioral and academic problems by third grade (10\%). Five children were identified after the fourth grade (17\%) and the remaining three children $(10 \%)$ were not identified with either behavioral or academic problems. These three individuals had dropped out of school during high school years.

The inmates provided a variety of recommendations and comments regarding their public school experiences. Twenty inmates (67\%) stated that their most positive experience in their education was their attendance at the alternative school. They commented that the classrooms were small and the individual attention from the teacher was greater than in the public schools. They stated the teachers had high expectations for them and they had to complete the school assignments. They also remarked they had to behave or else they would not get their reward or positive consequences. Additionally, they reported they were compliant as they did not want the punishment. A majority of inmates ( 25 inmates, $83 \%$ ) described their public school experiences as negative. They believed the teachers were ineffective in teaching styles, didn't care about whether they succeeded, labeled them as behavior problems, were "out to get them", and didn't expect them to achieve. Two of the inmates (6\%) had no preference between the two settings and three respondents (10\%) could not comment as they had dropped out of school and had not experienced an alternative school setting. These three individuals did not comment either positively or negatively regarding their public school experience.

\section{CONCLUSIONS AND FUTURE DIRECTIONS}

Public education has upheld many requirements toward the education of the children and youth that they teach. A great deal of attention has focused on academic accomplishments and assuring positive results on high stake testing. However, of equal importance is the social success of students in our public education settings. Without the development of good social skills that assures self monitoring, self regulation, delayed gratification and intrinsic monitoring of behaviors, success in the larger society may be destined for failure and in turn grave consequences for the individual and society.

Therefore, it is important that our educational system recognizes two very important factors: 1) students engaging in anti social behaviors must be recognized at an early age and social skills training must begin at this 
early age to assure future success for the student and 2) social skills training must focus on developing intrinsic control methods to develop appropriate social behaviors. There are two major findings that the research at the correctional facility revealed from the interviews and file reviews of the inmates. The data revealed: 1) the lack of early identification and early social skills training and 2) the over use of programs which enforced external measures to control behaviors. These findings could have been contributing factors to the incarceration of the subjects in this study. Past research clearly has revealed that early intervention is critical when dealing with maladjusted behaviors. Additionally, the use of programs which focus on external controls of behaviors may indeed match the way in which incarcerated individuals are dealt with in the correctional facility setting. If the latter is true, public education may have succeeded in educating individuals to succeed in a prison setting, but did not help in educating the individuals to succeed in a setting that requires self-monitoring behaviors to succeed in a free environment.

This study revealed that the inmates preferred a setting that had clear goals directed at getting rewards and avoiding further punishment. Additionally, the study revealed that for a majority of the inmates' interventions for appropriate social behaviors started in the later grades (middle and high school levels) even when behaviors problems were noted at an early age. These two practices of intervention that are currently being utilized in public education must be re-visited. Future research should focus on success rates of our students when social skill training begins at an early age and that these social skills programs focus on intrinsic social skill monitoring.

\section{AUTHOR INFORMATION}

Dr. Lawrence Ingalls is an Associate Professor at the University of Texas @ El Paso in the Department of Educational Psychology and Special Services. He has many years of teaching experience working with students with mild to severe disabilities including students with emotional and behavioral disturbances. A major area of interest for him has been on developing educational programs and assessment methodologies of students from culturally and linguistically diverse populations. Of particular interest is research involving American Indian children and their families. Additionally, Dr. Ingalls has devoted over ten years of research addressing educational issues with young offenders in our correctional institutions.

Dr. Helen Hammond is an Associate Professor at the University of Texas @ El Paso in the Department of Educational Psychology and Special Services. Her professional classroom experiences have primarily involved working in early childhood special education and with students with severe disabilities. Her major research interests have focused on family involvement in special education and early intervention. In addition to these areas, Dr. Hammond has spent over the past ten years, Dr. Hammond has been actively involved researching early intervention/educational and special education issues with young offenders in our prison systems.

\section{REFERENCES}

1. American Psychological Association. (1994). APA Government Report/Brochure on Youth Violence. Washington, D. C.: Author.

2. Cullinan, D. (2002). Students with emotional and behavioral disorders: An introduction for teachers and other helping professionals. Upper Saddle River, NJ: Merrill/Prentice-Hall.

3. Gonzalez-Mena, J. (2006). The young child in the family and the community (4 ${ }^{\text {th }}$ ed.). Upper Saddle River, NJ: Merrill/Prentice Hall.

4. Guralnick, M. (1997). The effectiveness of early intervention. Baltimore: Brookes.

5. Heward, W. (2006). Exceptional children: An introduction to special education. Upper Saddle River, NJ: Merrill/Prentice Hall.

6. Kaiser, B. \& Rasminsky, J. S. (2003). Challenging behavior in young children: Understanding, preventing, and responding effectively. Boston: Pearson.

7. Kauffman, J. M. (2005). Characteristics of emotional and behavioral disorders of children and youth $\left(8^{\text {th }}\right.$ ed.). Upper Saddle River, NJ: Merrill/Prentice Hall.

8. Lerner, J. W., Lowenthal, B., \& Egan, R. W. (2003). Preschool children with special needs: Children at risk, children with disabilities ( $2^{\text {nd }}$ ed.). Boston: Allyn and Bacon.

9. Paris, S. G. \& Paris, A. H. (2001). Classroom applications of research on self-regulated learning. Educational Psychologist, 36, 89-101. 
10. Raver, S. A. (2009). Early childhood special education - 0 to 8 years: Strategies for positive outcomes. Upper Saddle River, NJ: Pearson.

11. U. S. Department of Health and Human Services. (1999). Report of the Surgeon General's conference on Children's Mental Health: A national action agenda. Washington, DC: Author.

12. Vaughn, S., Bos, C., \& Schumm, J. (2007). Teaching students who are exceptional, diverse, and at risk in the general education classroom ( $4^{\text {th }}$ ed.). Boston: Pearson.

13. Wagner, M., Neuman, L., Cameto, R., Levine,P., \& Marder, C. (2003). Going to school: Instructional contexts, programs, and participation of secondary school students with disabilities. Menlo Park, CA: SRI International.

14. Walker, H. M., Colvin, G., \& Ramsey, E. (1995). Antisocial behavior in school: Strategies and best practices. Pacific Grove: Brooks/Cole.

15. Webber, J.\& Plotts, C. (2008). Emotional and behavioral disorders: Theory and practice (5 ${ }^{\text {th }}$ ed). Boston: Pearson.

16. Wolery, M. \& Bailey, D. (2002). Early childhood special education research. Journal of Early Intervention, 25(2), 88-99.

17. Zirpoli, T. J. (1995). Understanding and affecting the behavior of young children. Englewood Cliffs: Merrill. 
NOTES 